\title{
DONATILI ŞEV YAKININA OTURAN ŞERITT TEMEL DAVRANIŞININ SAYISAL İNCELEMESİ
}

\section{Buse EMIRLER*}

Çukurova Üniversitesi, Ceyhan Mühendislik Fakültesi, İnşaat Mühendisliği Bölümü, Adana, Türkiye

Anahtar Kelimele
SSev,
SSerit Temel,
Taşıma Gücü,
Güvenlik Katsayısı,
Sayısal Analiz.

Sayısal Analiz.

\begin{abstract}
Öz
Bu çalışmada, şev yakınına oturan şerit temeller ile ilgili taşıma gücü ve stabilite analizleri yapılmıştır. Örnek deneysel model doğrultusunda, şevli kum zemin yüzeyine yerleştirilen $\mathrm{B}=0.07 \mathrm{~m}$ genişliğinde bir şerit temel, şev tepesinden farklı mesafe oranlarında düșey yüke maruz bırakılmıștır. Analizlerde donatı kullanımının da taşıma gücüne ve güvenlik katsayısına olan etkileri incelenmiștir. Sayısal analizler, sonlu eleman yöntemine dayalı PLAXIS 3D bilgisayar programı kullanılarak yapılmıştır. Taşıma gücünün belirlenmesi amacıyla yapılan sayısal analizlerden elde edilen sonuçlar, literatürde yer alan deneylerle karşılaştırılmış ve üç boyutlu sayısal analizin taşıma gücünü tahminindeki başarısı araştırılmıştır. Temelin şev tepesinden uzaklığının ve donatı kullanımının güvenlik katsayısına olan etkisi ise parametrik olarak çalışılmıştır. Deney ve sayısal analizden elde edilen taşıma gücü sonuçlarının oldukça uyumlu olduğu görülmüş ve sonrasında yapılan parametrik çalışmada, temelin şev tepesine olan uzaklığının artması ve donatı kullanılması ile güvenlik katsayısının arttı̆̆ belirlenmiştir.
\end{abstract}

\section{NUMERICAL INVESTIGATION OF THE BEHAVIOUR OF STRIP FOOTING CONSTRUCTED NEAR REINFORCED SLOPE}

\begin{tabular}{l} 
Keywords \\
\hline Slope, \\
Strip Footing, \\
Bearing Capacity, \\
Safety Factor, \\
Numerical Analysis.
\end{tabular}

Alıntı / Cite

Emirler, B., (2020). Donatılı Şev Yakınına Oturan Şerit Temel Davranışının Sayısal İncelemesi, Mühendislik Bilimleri ve Tasarım Dergisi, 8(4), 1170-1179.

Yazar Kimliği / Author ID (ORCID Number)

B. Emirler, 0000-0002-0234-7177

\begin{abstract}
Abstract footings constructed near the slope. According to the example of experimental model presented, a strip footing in the width of $B=0.07 \mathrm{~m}$ placed on the slope which consists of sandy soil was subjected to an axial load at different distances from the slope top. In the analysis, the effects of the use of reinforcement on bearing capacity and safety factor were also examined. PLAXIS 3D software based on the finite element method was employed for numerical analyses. The results obtained from the numerical analysis conducted to determine the bearing capacity were compared with the experiments in the literature, and the success of the three-dimensional numerical analysis in predicting the bearing capacity was investigated. The effect of the distance of the footing from the top of the slope and the use of reinforcement on the safety factor were studied, parametrically. It is observed that the finite element results provide a highly fit with the experimental data obtained from the literature and in the parametric study performed afterwards, it is determined that the safety factor increases with the increase of the distance ratio of the footing to the top of the slope and with using reinforcement.
\end{abstract} (1) 


\section{Giriş (Introduction)}

Temeller, yapısal yükleri güvenli olarak zemine aktaran yapı elemanlarıdır. Yapısal yüklerin büyüklüğü, yönü, yer altı koşulları vb. faktörler inşa edilecek temelin yüzeysel ya da derin olması durumunu etkiler. Yüzeysel temellerin yük aktarımı esnasında, zeminde hem basınç hem de kayma gerilmeleri oluşur. Bu gerilmelerin büyüklükleri çoğunlukla temel taban basıncına ve temelin boyutlarına bağlıdır. Taban basıncının yeteri kadar büyük veya temelin yeteri kadar küçük olması, kayma gerilmelerinin zeminin kayma dayanımını aşmasına ve bu durumun taşıma gücü yenilmesi ile sonuçlanmasına sebep olabilir (Coduto, 2001). Temel zemininin problemli olması halinde en genel çözüm, derin temel seçilerek yapı temelinin tasarlanmasıdır. Fakat bu çözümün pahalı olması ve inşaat teknolojisindeki hızlı ilerleme, problemli zeminlerde yeni çözümler elde edilmesini zorunlu hale getirmiştir. Uygulamada sıklıkla kullanılan geoteknik çözümlerden biri, donatılı zemin uygulamasıdır. Zeminin taşıma gücünü artırmada ve oturmaları azaltmada geogridler sıklıkla kullanılmaktadır (Keskin, 2009).

Literatürde taşıma gücünü belirlemek için birçok yöntem mevcuttur (Prandtl, 1921; Terzaghi, 1943; Meyerhof, 1951; Balla, 1962; Brinch Hansen, 1970; Vesic, 1975). Terzaghi (1943) ve diğer taşıma gücü formülleri, düz (yatay) zemin yüzeyine oturan bir temel üzerine etkiyen düş̧ey yükleri dikkate alır. Ancak temellerin bir şev üzerine veya yakınına inşa edilmesi gerektiği durumlar da vardır. Yaklaşım dolguları üzerine oturan köprü ayakları, elektrik direkleri ve bazı bina yapıları örnek olarak verilebilir. Bir yapı temelinin șevli bir zemin üzerine inșa edildiği durumlarda taşıma gücü, eğimli olmayan zemine oranla şevin eğimine ve temelin konumuna göre önemli mertebelerde azalabilmektedir (Keskin, 2009). Şev yakınına oturan yüzeysel temellerin taşıma gücü ile ilgili ilk teorik çalışma Meyerhof (1957) tarafından gerçekleștirilmiştir. H yüksekliğinde bir șevin yakınına oturan B genişliğinde bir şerit temel, şev tepesinden $b$ kadar mesafeye yerleştirilmiştir (Şekil 1). Bu tür zeminler üzerindeki şerit temellerin taşıma gücü, kohezyonsuz zeminler (c=0) için Eşitlik 1 kullanılarak hesaplanmaktadır.

$$
\mathrm{q}_{\mathrm{u}}=0.5 \gamma \mathrm{BN}_{\gamma \mathrm{q}}
$$

Eşitlik 1'de; qu taşıma gücü, $\gamma$ zeminin birim hacim ağırlığı, B temel genişliği, $N_{\gamma q}$ ise taşıma gücü katsayısıdır. $B u$ katsayı; temel derinliği $\left(\mathrm{D}_{\mathrm{f}}\right)$, temel genişliği $(\mathrm{B})$, zeminin içsel sürtünme açısı $(\phi)$ ve şev tepesinden uzaklık (b) parametrelerine bağlı olarak belirlenmektedir (Das, 2011).

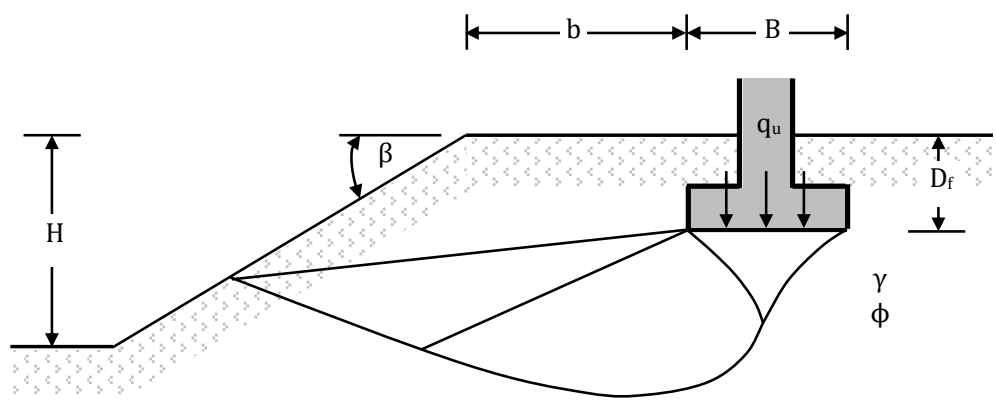

Şekil 1. Şev yakınına oturan yüzeysel temel (Shallow foundation constructed near slope) (Das, 2011)

Temelin şev üzerine inşa edildiği durumlarda, taşıma gücünün artırılması için uygulanabilecek çözümlerden biri, temelin şev tepesine yeterince uzak bir mesafeye yerleștirilerek, şevin taşıma kapasitesi üzerindeki etkisinin azaltılmasıdır. Ekonomik olmayan bu çözüm yerine kullanılabilecek yöntem ise taşıma kapasitesinin geogrid donatı kullanılarak artırılması olabilir.

Donatısız ve donatılı şevlere oturan şerit temellerle ilgili teorik ve deneysel çalışmalar literatürde mevcuttur (Graham vd., 1988; Gemperline, 1988; Saran vd., 1989; Selvadurai ve Gnanendran, 1989; Shields vd., 1990; Huang ve Tatsuoka, 1994; Huang vd., 1994; Lee ve Manjunath, 2000; Yoo, 2001; Bathurst vd., 2003; Blatz ve Bathurst, 2003; Keskin ve Laman, 2014). Ancak sayısal modellemeler ile ilgili çalışmalar oldukça sınırlıdır. Keskin vd. (2007) şevli kum zemine oturan şerit temellerin davranışını PLAXIS 2D bilgisayar programı ve Meyerhof yöntemini kullanarak araştırmışlardır. Şev açısının $30^{\circ}$ ve $35^{\circ}$ olması durumunda temelin şev tepesinden $5 \mathrm{~B}, 40^{\circ}$ olması durumunda ise 6B uzaklığa yerleştirilmesiyle şevsiz bir ortama benzer davranışın elde edildiğini gözlemlemişlerdir. Ayrıca Meyerhof yönteminin, sayısal analizden elde edilen sonuçlara kıyasla daha düşük değerler verdiğini belirtmişlerdir. Shiau ve Watson (2008) şev yakınına oturan yüzeysel bir temelin taşıma gücünü FLAC3D bilgisayar programını kullanarak araştırmışlardır. Çalışmada, temelin şev tepesinden uzaklık oranı D/B'nin 4'ten büyük olması durumunda şev etkisinin ortadan kalktığını görmüşlerdir. Ayrıca temel uzunluğunun artmasıyla taşıma gücünün azaldığı sonucuna ulaşmışlardır. Pınarlık vd. (2017) geotekstil kullanılan ve kullanılmayan şevlerin davranışını Slide2 bilgisayar programı ile araştırmışlardır. Şeve dolgu yapıldığında, güvenlik katsayısının arttığını ve bu artışın dolgulu șevin güçlendirilmesiyle daha fazla olduğunu belirlemişlerdir. 
Ayrıca kohezyon ve içsel sürtünme açısının artmasıyla güvenlik katsayısının arttığı sonucuna ulaşmışlardır. Keskin ve Akgül (2020) kumlu şevlerin yakınına oturan şerit temellerin taşıma gücü davranışını PLAXIS 2D bilgisayar programı ile araştırmışlardır. Analizlerde; şev açısı, zemin sıkılığı, temel genişliği ve temelin şev tepesine olan mesafesinin taşıma gücüne etkisini incelemişlerdir. Şev açısının artmasının taşıma gücünü azalttığını; zemin sıkılığı, temel genişliği ve temelin şev tepesine uzaklığının artmasının ise taşıma gücünü artırdığını belirlemişlerdir. Şev açısının artmasıyla güvenlik katsayısının azaldığını, zemin sıkılığının artmasıyla ise güvenlik katsayısının arttığını gözlemlemişlerdir. Ayrıca analizler sonucunda elde edilen göçme mekanizmalarının şev yüzeyinde oluştuğunu ve temeli şev tepesinden uzaklaştırdıkça mekanizma üzerinde şev etkisinin ortadan kalktığını görmüşlerdir.

Bu çalışmada, şevli kum zemin yakınına oturan şerit temeller ile ilgili taşıma gücü ve stabilite analizleri yapılmıştır. Analizlerde sonlu eleman yöntemine dayalı PLAXIS 3D bilgisayar programı kullanılmıştır. Zemin yüzeyinin düz $\left(0^{\circ}\right)$ ve $30^{\circ}$ eğimli olduğu durumda yapılan analizlerde, temelin şev tepesine olan mesafe oranının (b/B), donatı kullanımının $(\mathrm{N}=1)$ ve donatı uzunluğunun $\left(\mathrm{L}_{\mathrm{R}}\right)$ taşıma gücü ve güvenlik katsayısına olan etkileri incelenmiştir. Taşıma gücünün belirlenmesi amacıyla yapılan sayısal analizlerden elde edilen sonuçlar, literatürde yer alan deneylerle karşılaștırılmış ve sayısal analizin taşıma gücünü tahminindeki başarısı araştırılmıștır. Temelin şev tepesinden uzaklığının ve donatı kullanımının güvenlik katsayısına olan etkileri ise parametrik olarak çalışılmıştır.

\section{Materyal ve Yöntem (Material and Method)}

Çalıșmada, şevli kum zemine oturan şerit temelin sayısal analizi sonlu eleman yöntemine dayalı PLAXIS 3D bilgisayar programı ile gerçekleştirilmiştir. Analizlerde çalışma ortamının geometrik modeli, Keskin (2009) tarafından yapılan çalışma ışığında, üç boyutlu ve ele alınan şerit temel problemine uygun olarak oluşturulmuştur. Geometrik modelin genişliği $1.140 \mathrm{~m}$, uzunluğu $0.475 \mathrm{~m}$ ve yüksekliği ise $0.450 \mathrm{~m}$ 'dir. Analizler, zemin yüzeyinin düz $\left(0^{\circ}\right)$ ve şev açısının $\beta=30^{\circ}$ olduğu durumlar için yapılmıştır. Zemin modeli olarak Mohr-Coulomb (MC) tercih edilmiştir. Geoteknik mühendisliği problemlerinin analizinde zeminlerin davranışı; az sayıda model parametresine ihtiyaç duyulması, geoteknik mühendislerinin gerekli model parametrelerine aşina olmaları, içsel sürtünme açısı ve kohezyon gibi basit fiziksel özellikler kullanılarak göçme kriteri tanımlama olanağının bulunması ve zemin numuneleri üzerinde gerçekleştirilecek temel zemin mekaniği laboratuvar deneyleriyle bu parametrelerin kolaylıkla elde edilebiliyor olması gibi nedenler ile yaygın olarak Mohr-Coulomb malzeme modeli ile araştırılabilmektedir (Emirler vd., 2019). MC model için zemin parametreleri, deneyler sonucunda elde edilmiştir (Tablo 1). Deneylerden elde edilen kohezyon değeri her ne kadar c=0 olsa da, program, kohezyon (c) değerinin 0 alınması durumunda analizlerde formülasyondan dolayı bazı sıkıntılar doğabileceğini belirtmiş ve kohezyonun $0.2 \mathrm{kN} / \mathrm{m}^{2}$ den büyük alınmasını önermiştir (Plaxis 3D Material Models Manual, 2019). Bu sebeple analizlerde kohezyon değeri $\mathrm{c}=0.4 \mathrm{kN} / \mathrm{m}^{2}$ olarak alınmıştır. Şerit temel, plate olarak modellenmiștir. Eleman parametreleri olarak çelik malzemenin özellikleri kullanılmış ve girdi parametreleri Tablo 2'de verilmiştir. Temel; $0.07 \mathrm{~m}$ genişlikte, $0.465 \mathrm{~m}$ uzunlukta ve $0.02 \mathrm{~m}$ yükseklikte modellenmiștir. Donatılı analizlerde ise donatı olarak geogrid yapısal elemanı kullanılmış ve eksenel rijitlik değeri EA=1100kN/m² alınmıştır (Keskin, 2009). Donatı ile zemin arasındaki etkileşim ara yüz elemanı vasıtasıyla dikkate alınmış ve literatüre uygun olarak mukavemet azaltma faktörü Rinter=0.90 seçilmiştir (Faizi vd., 2013).

Tablo 1. Kum zemin için parametreler (Parameters for sandy soil)

\begin{tabular}{cc}
\hline PARAMETRE & DEĞER \\
\hline Malzeme modeli & MC \\
Drenaj türü & Drenajlı \\
Kuru birim hacim ağırlık, $\gamma$ unsat $\left(\mathrm{kN} / \mathrm{m}^{3}\right)$ & 17.0 \\
Elastisite modülü, E $\left(\mathrm{kN} / \mathrm{m}^{2}\right)$ & 28000 \\
Poisson oranı, $v$ & 0.25 \\
Kohezyon, c $\left(\mathrm{kN} / \mathrm{m}^{2}\right)$ & 0.4 \\
İçsel sürtünme açısı, $\phi\left(^{\circ}\right)$ & 41.8 \\
Dilatasyon açısı, $\Psi\left(^{\circ}\right)$ & 11.8 \\
\hline
\end{tabular}

Tablo 2. Şerit temel için parametreler (Parameters for strip footing)

\begin{tabular}{cc}
\hline PARAMETRE & DEĞER \\
\hline Kalınlık, d $(\mathrm{m})$ & 0.02 \\
Birim hacim ağırlık, $\gamma\left(\mathrm{kN} / \mathrm{m}^{3}\right)$ & 77.0 \\
Elastisite modülü, $\mathrm{E}\left(\mathrm{kN} / \mathrm{m}^{2}\right)$ & $2 \times 10^{8}$ \\
Poisson oranı, $v$ & 0.3 \\
\hline
\end{tabular}


PLAXIS 3D'de sonlu elemana ayırma işlemi otomatik olarak gerçekleștirilmekte, ayrıca istenilen bölgelerde ağ sıkılaştırması seçeneği sunulmaktadır. Bu çalışmada, sonlu eleman ağı orta sıkılıkta (medium) oluşturulmuş ve temel etrafında sıkılaştırma işlemi yapılmıştır. Donatının kullanılmadığı şevsiz durumda yapılan analizlerde çalışma ortamı, 32193 dört yüzlü (tetrahedral) eleman ve 48122 düğüm noktasından oluşmuştur. Şevli durumda ise 21560 eleman ve 32960 dügüm noktası meydana gelmiştir (Şekil 2). Taşıma gücü analizlerinde hesaplama türü "Plastic", güvenlik katsayısı analizleri için ise "Safety" seçilmiştir. Ayrıca şevsiz durum için başlangıç koşulları "K 0 procedure" ile, şevli durumda ise "Gravity loading" ile oluşturulmuştur.

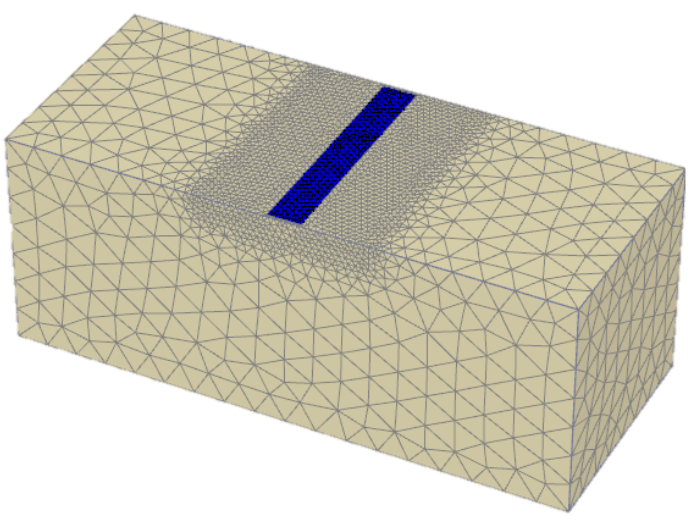

(a) şevsiz

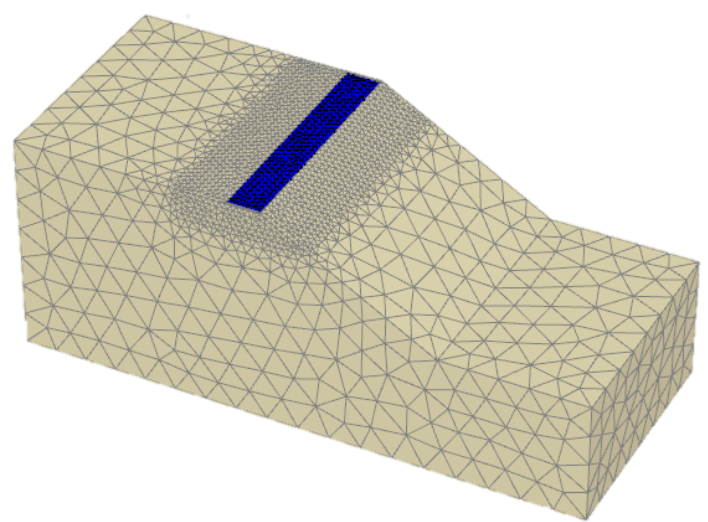

(b) şevli

Şekil 2. Sonlu eleman ağı (Finite element mesh)

Modelde araştırılan parametrelere ilişkin görsel Şekil 3'te verilmiştir. Çalışma boyunca; donatısız durumdaki şev yakınına oturan $B=0.07 \mathrm{~m}$ genişliğinde bir şerit temelde, $b / B=0,1,2,3$, 4 ve 5 olmak üzere altı farklı mesafe oranının taşıma gücünde ve güvenlik katsayısında meydana getirdiği değişim incelenmiştir. Donatılı analizler ise $b / B=1$ olmak üzere sabit bir mesafe oranında yapılmış ve donatı uzunluğunun $L_{R}=x+1 B, x+2 B, x+3 B, x+4 B, x+5 B$, $\mathrm{x}+6 \mathrm{~B}$ ve $\mathrm{x}+7 \mathrm{~B}$ olmasının taşıma gücü ve güvenlik katsayısına etkileri araştırılmıștır.

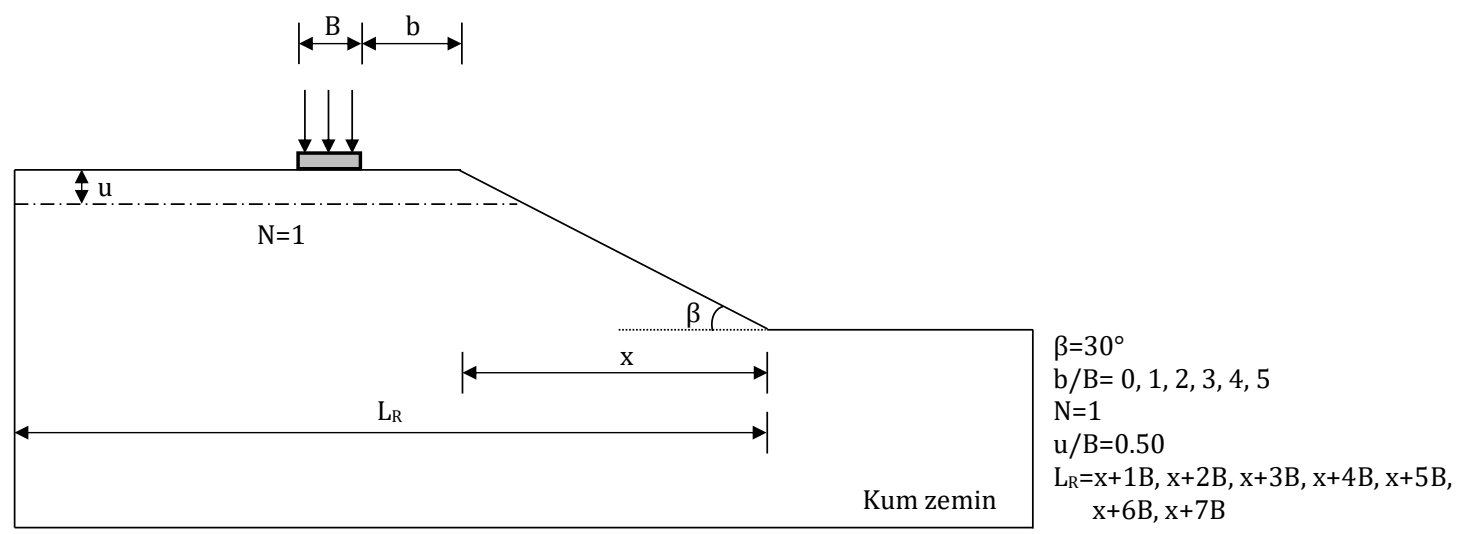

Şekil 3. Model geometrisi (Model geometry)

\section{Bulgular ve Tartışma (Findings and Discussion)}

Sayısal modelleme yapılan bu çalıșmada; üç boyutlu analizin başarısı, Keskin (2009) tarafından yapılan deneyler kullanılarak araştırılmıştır. Şerit temelin şev tepesinden uzaklığının ve donatı kullanımının taşıma gücü ve güvenlik katsayısına olan etkileri iki ayrı başlık halinde sunulmuştur.

\subsection{Taşıma Gücü (Bearing Capacity)}

Analizlerde; $B=0.07 \mathrm{~m}$ genişliğinde şerit temel, şev açısı $\beta=30^{\circ}$ olan bir şevin tepesine farklı mesafe oranlarında $\left(b / B=0,1,2,3,4\right.$ ve 5) yerleştirilerek modellenmiştir. Ayrıca zemin yüzeyinin düz olduğu durum için $\left(\beta=0^{\circ}\right)$ yapılan analizle, şevin taşıma gücünde ve göçme mekanizmasında yarattığı değişimin incelenmesi sağlanmıştır. Tablo 3'te şevsiz ve şevli durum için yapılan analizlere ait sonuçlar verilmiştir. Elde edilen sonuçların deneylerle oldukça uyumlu olduğu görülmüştür. Deney ve sayısal analiz arasında maksimum \%2.8, minimum ise $\% 0.08$ fark elde edilmiștir ve bu farklar kabul edilebilir değerlerdedir. MC zemin modelinin az sayıda model parametresi içermesine rağmen modellemedeki başarısı, geoteknik problemlerin davranış tahmininde bu modelin kullanılabilir olduğunu göstermiştir. Temelin şev tepesinden uzaklaşmasıyla taşıma gücü önemli oranda artmıştır. 
Şevsiz durumdaki taşıma gücü değeri $127.95 \mathrm{kN} / \mathrm{m}^{2}$ iken, temelin şev tepesine olan mesafe oranın $\mathrm{b} / \mathrm{B}=1$ olduğu durumda taşıma gücünün $31.55 \mathrm{kN} / \mathrm{m}^{2}$ ye düștüğü ve yaklaşık 4 kat azaldığı görülmüştür. b/B=5 olduğunda elde edilen taşıma gücü değeri ise şevsiz durumda elde edilen taşıma gücü değeriyle neredeyse aynı çıkmıştır. Bu durumda b/B=5 mesafe oranında, temelin taşıma gücü üzerinde şevin bir etkisinin olmadığı söylenebilir.

Tablo 3. Donatısız durum için taşıma gücü analiz sonuçları (Bearing capacity analysis results for unreinforced case)

\begin{tabular}{cccc}
\hline $\boldsymbol{\beta}$ & $\mathbf{b} / \mathbf{B}$ & $\begin{array}{c}\text { DENEY } \\
\left(\mathrm{kN} / \mathrm{m}^{2}\right)\end{array}$ & $\begin{array}{c}\text { SAYISAL ANALIZ } \\
\left(\mathrm{kN} / \mathrm{m}^{2}\right)\end{array}$ \\
\hline 0 & - & 130.40 & 127.95 \\
30 & 0 & 31.50 & 31.55 \\
30 & 1 & 56.70 & 56.27 \\
30 & 2 & 72.86 & 74.80 \\
30 & 3 & 90.27 & 90.20 \\
30 & 4 & 109.11 & 110.55 \\
30 & 5 & 124.40 & 127.88 \\
\hline
\end{tabular}

Araştırılan parametrenin göçme mekanizmasına olan etkisi incelendiğinde şevsiz durumda $\left(\beta=0^{\circ}\right)$ temel altında düzgün bir deplasman dağılımı elde edilmiștir. Ancak şevli durumda $\left(\beta=30^{\circ}\right)$ şev tepesine yakın mesafe oranlarında göçme mekanizmasının şevden etkilendiği, $b / B=3$ 'ten sonra ise düz bir zemine oturan şerit temelin göçme mekanizmasına benzer göçme mekanizmalarının elde edilmeye başlandığı görülmüştür (Şekil 4). Analiz sonuçlarından temelin şev tepesine olan mesafesinin, taşıma gücünü etkileyen önemli bir parametre olduğu doğrulanmıştır.

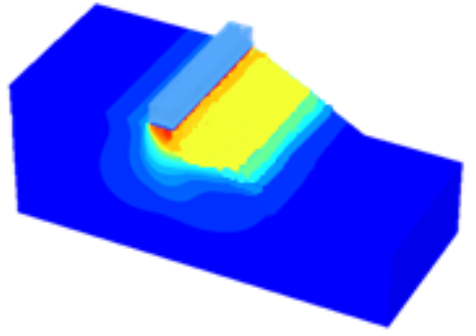

(b) $b / B=0$

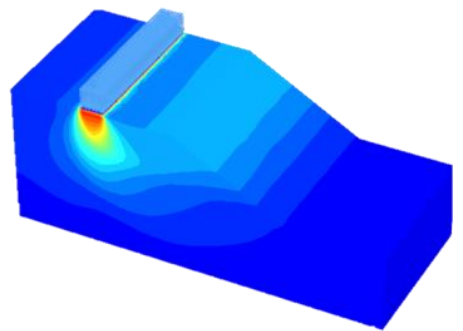

(e) $b / B=3$

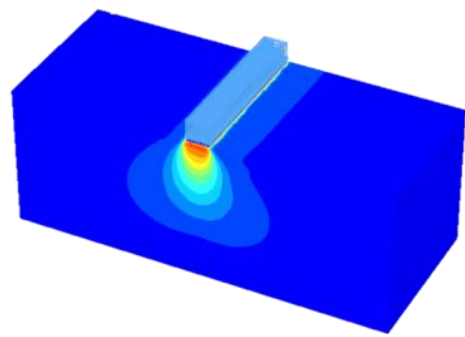

(a) şevsiz

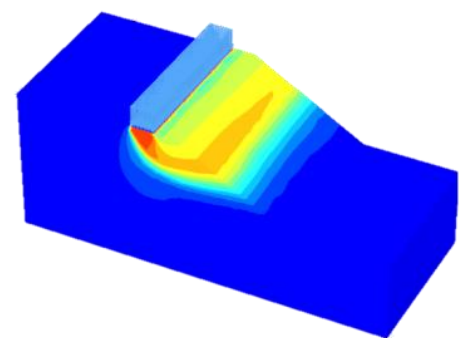

(c) $b / B=1$

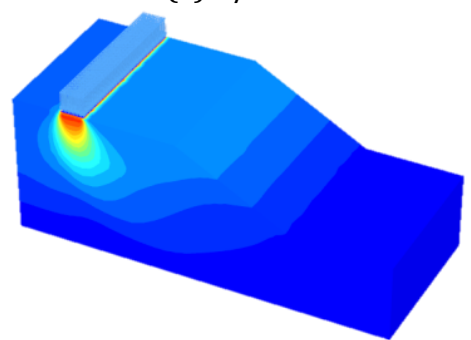

(f) $b / B=4$

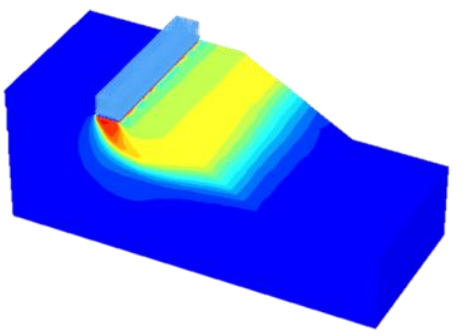

(d) $b / B=2$

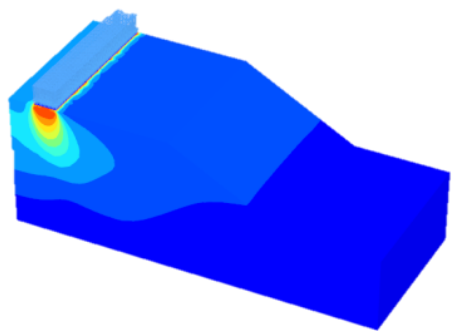

(g) $b / B=5$

Şekil 4. Taşıma gücü analizi için $b / B$ 'nin göçme mekanizmasına etkisi (Effect of b/B on failure mechanism for bearing capacity analysis)

Donatının taşıma gücüne etkisini incelemek için $b / B=1$ mesafe oranında farklı donatı uzunlukları $\left(L_{R}=x+1 B, x+2 B\right.$, $x+3 B, x+4 B, x+5 B, x+6 B$ ve $x+7 B$ ) için analizler yapılmıștır. Analizlerde donatı sayısı $N=1$ ve donatı derinliği oranı $\mathrm{u} / \mathrm{B}=0.50$ olarak sabit tutulmuştur. Parametrenin hem taşıma gücü hem de göçme mekanizmasına olan etkileri incelenmiştir. Temelin taşıma gücüne ait sonuçlar Tablo 4'te verilmiş ve sayısal analiz sonuçlarının deneylerle uyum içinde olduğu görülmüștür. Donatı uzunluğunun artmasıyla temelin taşıma gücü önemli oranda artmış, 
ancak $L_{R}=x+5 B$ 'den sonra bu artış miktarı oldukça azalmıştır. Donatı uzunluğunun $L_{R}=x+1 B$ olduğu durumda taşıma gücü değeri $58.50 \mathrm{kN} / \mathrm{m}^{2}$ iken, $\mathrm{L}_{\mathrm{R}}=\mathrm{x}+7 \mathrm{~B}^{\prime}$ de bu değer $104.94 \mathrm{kN} / \mathrm{m}^{2}$ olarak elde edilmiştir. Bu iki donatı uzunluğundaki taşıma güçleri kıyaslandığında meydana gelen artış yaklaşık \%80, $\mathrm{L}_{\mathrm{R}}=\mathrm{x}+5 \mathrm{~B}$ ile $\mathrm{L}_{\mathrm{R}}=\mathrm{x}+7 \mathrm{~B}$ arasında ise yaklaşık \%6 civarında olmuştur. Ayrıca donatısız durumda elde edilen taşıma gücü değerinin $56.27 \mathrm{kN} / \mathrm{m}^{2}$, donatılı durumda elde edilen maksimum değerin ise $104.94 \mathrm{kN} / \mathrm{m}^{2}$ olduğu görülmüştür. Sonuç olarak, tek donatının dahi tașıma gücünü yaklașık 2 kat artırdığı belirlenmiștir.

Tablo 4. Donatılı durum için taşıma gücü analiz sonuçları (Bearing capacity analysis results for reinforced case)

\begin{tabular}{ccc}
\hline $\begin{array}{c}\mathbf{L}_{\mathbf{R}} \\
(\mathrm{m})\end{array}$ & $\begin{array}{c}\text { DENEY } \\
\left(\mathrm{kN} / \mathrm{m}^{2}\right)\end{array}$ & $\begin{array}{c}\text { SAYISAL ANALIZ } \\
\left(\mathrm{kN} / \mathrm{m}^{2}\right)\end{array}$ \\
\hline Donatısız & 56.70 & 56.27 \\
x+1B & 60.81 & 58.50 \\
x+2B & 70.06 & 72.11 \\
x+3B & 83.68 & 84.50 \\
x+4B & 92.12 & 92.10 \\
x+5B & 101.66 & 98.67 \\
x+6B & 105.19 & 102.80 \\
x+7B & 108.33 & 104.94 \\
\hline
\end{tabular}

Araştırılan parametrenin göçme mekanizmasına olan etkisi incelendiğinde donatısız durumda temel altında meydana gelen deplasman yoğunluğunun fazla olduğu ve şevden etkilendiği görülmüştür. Donatı kullanılmasıyla birlikte yoğunluğun hafiflediği ve donatı uzunluğunun $L_{R}=x+5 B$ olmasıyla birlikte şevin, göçme mekanizmasında oluşturduğu etkinin azaldığ belirlenmiştir. (Şekil 5). $L_{R}=x+5 B$ ile $x+7 B$ için elde edilen göçme mekanizmalarının benzer olduğu ve ekonomi de düşünüldüğünde, $x+5 B$ donatı uzunluğunun optimum bir değer olarak kabul edilebileceği söylenebilir. Analiz sonuçları ile donatı kullanımının ve donatı uzunluğunun, taşıma gücü üzerinde önemli bir etkiye sahip olduğu görülmüştür.

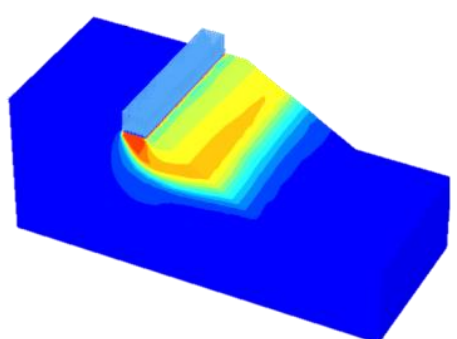

(a) donatısız

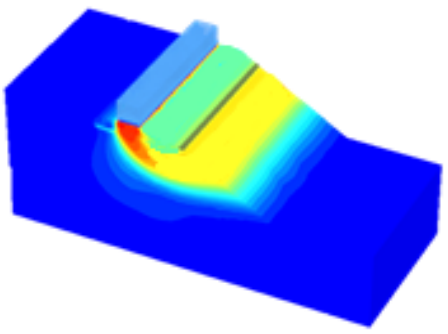

(d) $L_{R}=x+3 B$

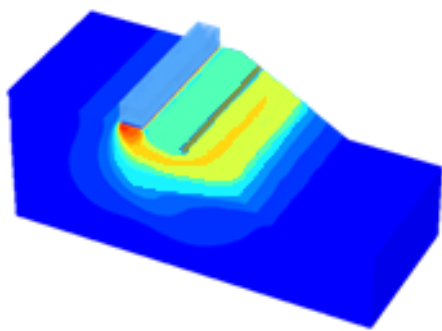

(b) $L_{R}=x+1 B$

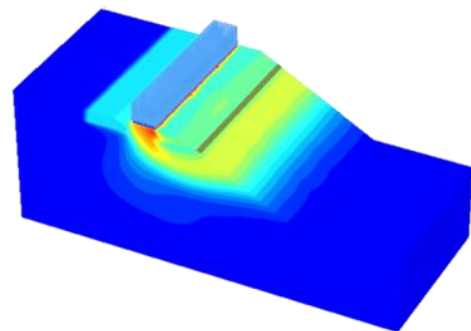

(e) $L_{R}=x+4 B$

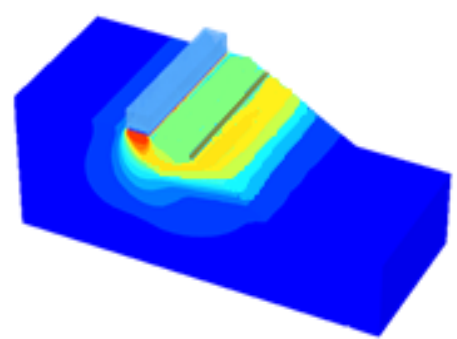

(c) $L_{R}=x+2 B$

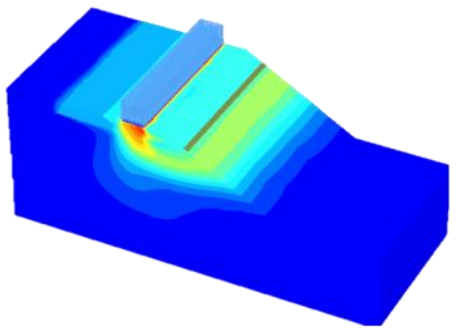

(f) $L_{R}=x+5 B$

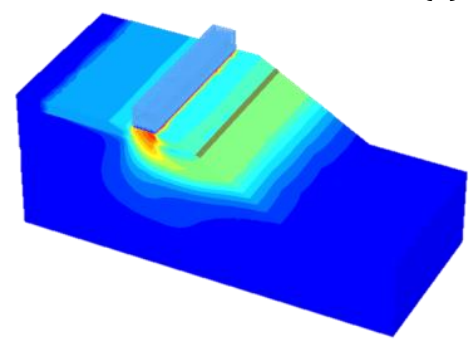

(g) $\mathrm{L}_{\mathrm{R}}=\mathrm{x}+6 \mathrm{~B}$

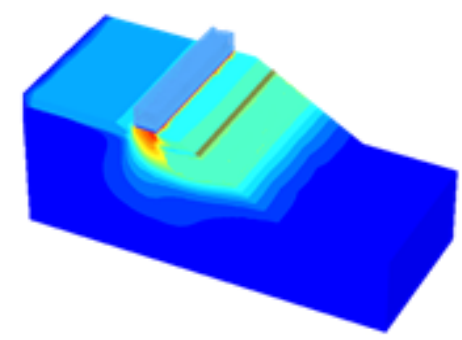

(h) $L_{R}=x+7 B$

Şekil 5. Taşıma gücü analizi için $L_{R}$ 'nin göçme mekanizmasına etkisi (Effect of $L_{R}$ on failure mechanism for bearing capacity analysis) 


\subsection{Güvenlik Katsayısı (Safety Factor)}

Analizlerde ele alınan model üzerinde güvenlik katsayısının tespiti, "Safety" hesaplama türü kullanılarak yapılmıştır. Her bir analiz için temel üzerinde $30 \mathrm{kN} / \mathrm{m}^{2}$ 'lik yüzey yükü (surface load) olduğu varsayılmıştır. Tablo 5 'te şev tepesinden farklı mesafe oranları için elde edilen güvenlik katsayıları verilmiştir. Sonuçlara göre temelin şev tepesinden daha uzak bir noktaya konumlandırılmasının, şev stabilitesi üzerinde önemli bir etkiye sahip olduğu ve mesafe oranın artmasıyla güvenlik katsayısının arttığı görülmüştür. Elde edilen minimum ve maksimum güvenlik katsayıları arasında yaklaşık 1.5 katlık bir fark olduğu belirlenmiștir. Ancak bu fark, b/B=3 ile b/B=5 arasında yaklaşık \%6 civarında küçük bir değerdir. Dolayısıyla temelin b/B=3 mesafe oranından daha uzak bölgelere yerleştirilmesinin, stabiliteye önemli bir katkısının olmadığı anlaşılmıştır.

Tablo 5. Donatısız durum için güvenlik katsayısı analiz sonuçları (Safety factor analysis results for unreinforced case)

\begin{tabular}{cc}
\hline b/B & $\begin{array}{c}\text { GÜVENLIK } \\
\text { KATSAYISI }\end{array}$ \\
\hline 0 & 1.05 \\
1 & 1.25 \\
2 & 1.38 \\
3 & 1.49 \\
4 & 1.54 \\
5 & 1.58 \\
\hline
\end{tabular}

Elde edilen bu sayısal sonuçlar göçme mekanizmalarıyla da desteklenmiştir. b/B=4 ve 5 mesafe oranları için şevin göçme mekanizmasına herhangi bir etkisi olmamıştır. Üstelik b/B=5 mesafe oranı için modelde sınır etkisinin ortaya çıtı̆̆ı ve bu durumun mekanizmada anlamsız bir yoğunluğa sebep olduğu görülmüştür (Şekil 6).

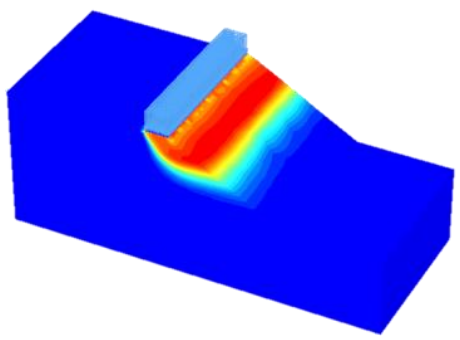

(a) $b / B=0$

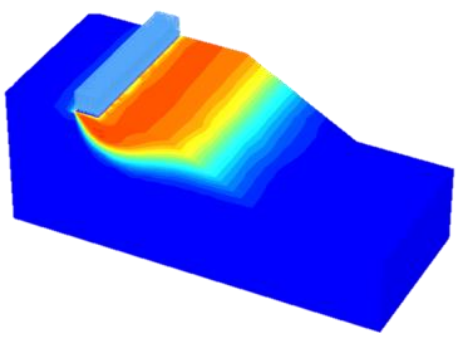

(d) $b / B=3$

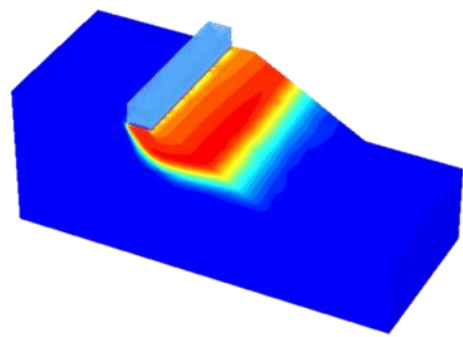

(b) $b / B=1$

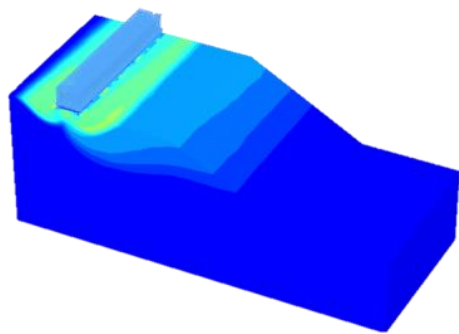

(e) $b / B=4$

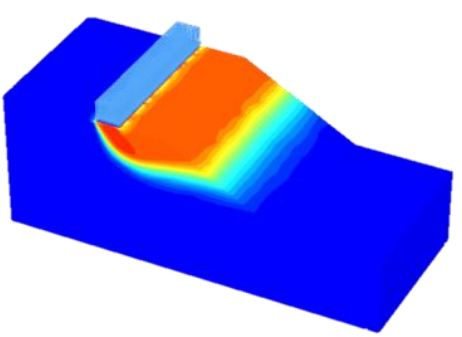

(c) $b / B=2$

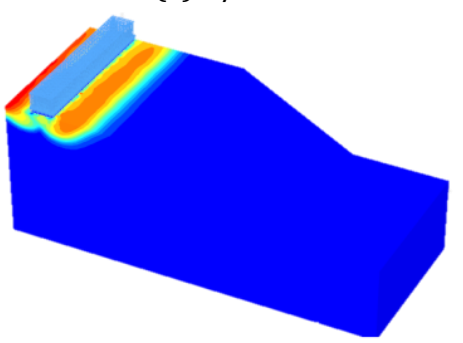

(f) $b / B=5$

Şekil 6. Güvenlik katsayısı analizi için b/B'nin göçme mekanizmasına etkisi (Effect of b/B on failure mechanism for safety factor analysis)

Donatı kullanımının güvenlik katsayısına etkisi de araştırılmıştır. Şev tepesine mesafe oranının $b / B=1$ olduğu, $30 \mathrm{kN} / \mathrm{m}^{2}$ lik yüke maruz temel modelinde; $\mathrm{L}_{\mathrm{R}}=\mathrm{x}+1 \mathrm{~B}, \mathrm{x}+2 \mathrm{~B}, \mathrm{x}+3 \mathrm{~B}, \mathrm{x}+4 \mathrm{~B}, \mathrm{x}+5 \mathrm{~B}, \mathrm{x}+6 \mathrm{~B}$ ve $\mathrm{x}+7 \mathrm{~B}$ donatı uzunlukları için analizler yapılmıș ve sonuçlar Tablo 6'da sunulmuştur. Donatısız durumda elde edilen güvenlik katsayısı 1.25 iken, donatı uzunluğunun $\mathrm{x}+1 \mathrm{~B}$ olduğu durumda güvenlik katsayısı 1.27 olarak elde edilmiştir. Diğer bir ifade ile bu uzunluğun stabilite üzerinde pek bir etkiye sahip olmadığı görülmüştür. $L_{R}=x+7 B$ donatı uzunluğunda ise güvenlik katsayısının 1.48 olduğu tespit edilmiştir. $L_{R}=x+5 B$ ve $x+7 B$ donatı uzunlukları arasında güvenlik katsayısındaki artış yaklașık \%2 gibi az bir düzeyde meydana gelmiş, ekonomi de göz önüne alındığında $L_{R}=x+5 B$ uzunluğunda donatı kullanımının daha makul olduğu belirlenmiştir.

Araştırılan parametrenin göçme mekanizmasına olan etkisi incelendiğinde, donatısız durumda temel altında meydana gelen deplasman yoğunluğunun oldukça fazla olduğu görülmüștür. Donatı kullanılmasıly birlikte yoğunluğun azalmaya başladığ $\mathrm{L}_{\mathrm{R}}=\mathrm{x}+5 \mathrm{~B}$ ve sonrasında ise bu azalmanın maksimum düzeyde olduğu ve neredeyse 
sabitlendiği belirlenmiştir (Şekil 7). Analiz sonuçları ile donatı kullanımı ve donatı uzunluğu parametrelerinin, güvenlik katsayısı üzerinde de önemli bir etkiye sahip olduğu tespit edilmiştir.

Tablo 6. Donatılı durum için güvenlik katsayısı analiz sonuçları (Safety factor analysis results for reinforced case)

\begin{tabular}{cc}
\hline \multicolumn{1}{c}{$\mathbf{L}_{\mathbf{R}}$} & $\begin{array}{c}\text { GÜVENLIK } \\
\text { KATSAYISI }\end{array}$ \\
\hline Donatısız & 1.25 \\
$\mathrm{x}+1 \mathrm{~B}$ & 1.27 \\
$\mathrm{x}+2 \mathrm{~B}$ & 1.34 \\
$\mathrm{x}+3 \mathrm{~B}$ & 1.39 \\
$\mathrm{x}+4 \mathrm{~B}$ & 1.41 \\
$\mathrm{x}+5 \mathrm{~B}$ & 1.45 \\
$\mathrm{x}+6 \mathrm{~B}$ & 1.47 \\
$\mathrm{x}+7 \mathrm{~B}$ & 1.48 \\
\hline
\end{tabular}

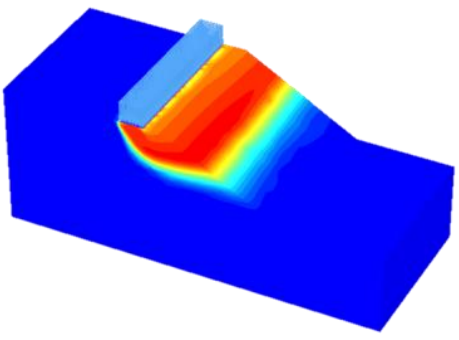

(a) donatısız

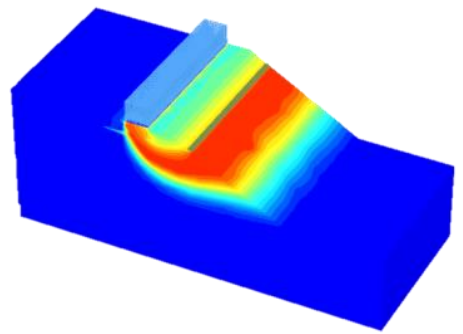

(d) $L_{R}=x+3 B$

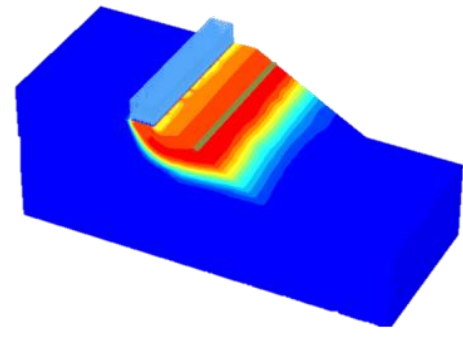

(b) $L_{R}=x+1 B$

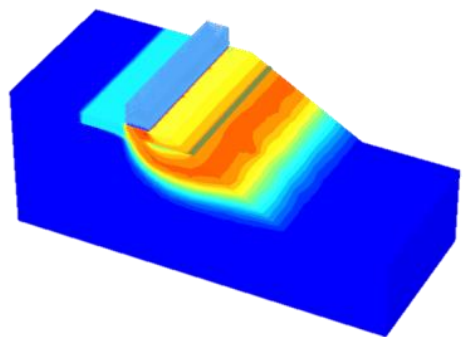

(e) $L_{R}=x+4 B$

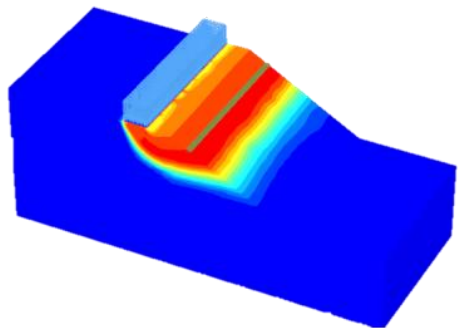

(c) $\mathrm{L}_{\mathrm{R}}=\mathrm{x}+2 \mathrm{~B}$

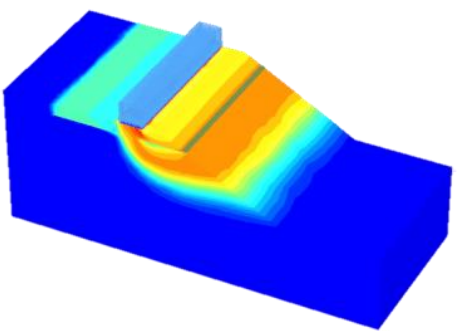

(f) $\mathrm{L}_{\mathrm{R}}=\mathrm{x}+5 \mathrm{~B}$

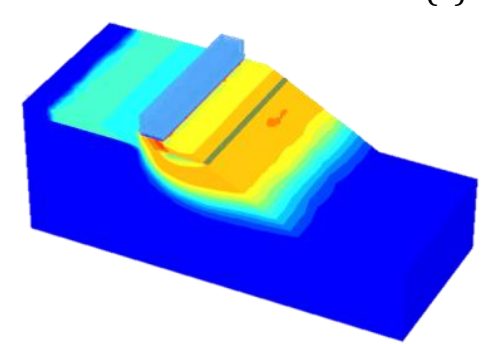

(g) $L_{R}=x+6 B$

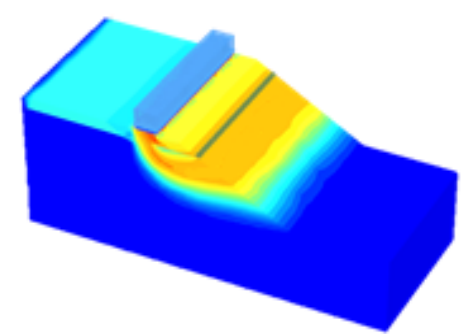

(h) $L_{R}=x+7 B$

Şekil 7. Güvenlik katsayısı analizi için $L_{R}$ 'nin göçme mekanizmasına etkisi (Effect of $L_{R}$ on failure mechanism for safety factor analysis)

\section{Sonuç (Conclusion)}

Bu çalışmada, şevli kum zemin yakınına oturan şerit temeller ile ilgili taşıma gücü ve stabilite analizleri yapılmıştır. Taşıma gücünün belirlenmesi amacıyla yapılan sayısal analizlerden elde edilen sonuçlar, literatürde yer alan deneylerle karşılaştırılmış, temelin şev tepesine uzaklığının ve donatı kullanımının güvenlik katsayısına olan etkileri ise parametrik olarak çalıșılmıştır. Araştırılan parametrelerin taşıma gücü, güvenlik katsayısı ve göçme mekanizmasına olan etkileri, sonlu eleman yöntemine dayalı üç boyutlu sayısal analiz programı ile başarılı bir şekilde yansıtılmış ve elde edilen sonuçlar aşağıda sunulmuştur.

- Temelin șev tepesine olan mesafe oranı arttıkça tașıma gücü artmıș ve mesafe 5B olduğunda elde edilen tașıma gücü değeri, zemin yüzeyinin düz olduğu durumdakiyle yakın çıkmıştır. Göçme mekanizmaları incelendiğinde, b/B=3'e kadar olan mesafe oranlarında şevin temel davranışı üzerinde oldukça etkili olduğu, ancak bu değerden 
sonra elde edilen göçme mekanizmalarının düz yüzeyli bir zemin durumunda elde edilen göçme mekanizmasına benzer olduğu görülmüștür. Ayrıca donatı kullanımının temelin taşıma gücünü önemli oranda artırdığı ve göçme mekanizmaları incelendiğinde, șevde meydana gelen deplasman yoğunluğunu sönümlediği belirlenmiştir.

- Şevli zemin durumu için yapılan stabilite analizlerinde, temelin şev tepesinden uzaklaşmasıyla güvenlik katsayısı artmış ve bu artış yaklaşık 1.5 kat civarında olmuştur. Göçme mekanizmaları incelendiğinde, $b / B=4$ ve 5 mesafe oranlarında şevin mekanizma üzerinde etkisinin kalmadığı görülmüștür. Ayrıca donatı kullanımının stabiliteyi olumlu yönde etkilediği ve güvenlik katsayısını iyileștirdiği tespit edilmiştir. Buna karşın, $L_{R}=x+5 B$ 'den daha uzun donatı kullanımının ise stabiliteye önemli bir katkısının olmadığı göçme mekanizmalarından da açıkça anlaşılmıştır.

Bu çalışma, literatürdeki deneyler ile modeli doğrulamaya yönelik olduğundan elde edilen sayısal sonuçlar gerçek boyutlu değerleri yansıtamayabilir. Bu sebeple gerçek projeler/modellemeler için ölçek ve boyut etkisinin göz ardı edilmemesi gerekmektedir. Ayrıca mevcut deneysel çalışmada şerit temel malzemesi çelik olduğundan, sayısal çalışmada da bu malzemeye ait özellikler tanımlanmıştır. Ancak uygulamada, betonarme malzemenin bu seviyede bir rijit davranış yerine daha esnek bir davranıș sergileyeceği unutulmamalıdır.

\section{Çıkar Çatıșması (Conflict of Interest)}

Yazar tarafından herhangi bir çıkar çatışması beyan edilmemiştir. No conflict of interest was declared by the author.

\section{Kaynaklar (References)}

Balla, A., 1962. Bearing Capacity of Foundations. Journal of the Soil Mechanics and Foundations, 88(5), 13-34.

Bathurst, R.J., Blatz, J.A., Burger, M.H., 2003. Performance of Instrumented Large-Scale Unreinforced and Reinforced Embankments Loaded by a Strip Footing to Failure. Canadian Geotechnical Journal, 40(6), 1067-1083.

Blatz, J.A., Bathurst, R.J., 2003. Limit Equilibrium Analysis of Large-Scale Reinforced and Unreinforced Embankments Loaded by a Strip Footing. Canadian Geotechnical Journal, 40(6), 1084-1092.

Brinch Hansen, J., 1970. A Revised and Extended Formula for Bearing Capacity", The Danish Geotechnical Institute, 28, 5-11.

Coduto, D.P., 2001. Foundation Design: Principles and Practices. Prentice Hall, New Jersey.

Das, B.M., 2011. Principles of Foundation Engineering. Cengage Learning, Connecticut.

Emirler, B., Tolun, M., Yıldız, A., 2019. Eğik Çekme Yükü Etkisindeki Tekil Kazığın Üç Boyutlu Sayısal Analizi. Çukurova Üniversitesi Mühendislik Mimarlık Fakültesi Dergisi, 34(2), 219-229.

Faizi, K., Armaghani, D.J., Kassim, A., Lonbani, M., 2013. Evaluation of Geotextiles on Embankment Displacement under Seismic Load. The Electronic Journal of Geotechnical Engineering, 18(C), 439-449.

Gemperline, M.C., 1988. Centrifugal Modeling of Shallow Foundations. ASCE Spring Convention, Nashville, 45-70.

Graham, J., Andrews, M., Shields, D.H., 1988. Stress Characteristics for Shallow Footings in Cohesionless Slopes. Canadian Geotechnical Journal, 25(2), 238-249.

Huang, C.C., Tatsuoka, F., 1994. Stability Analysis for Footings on Reinforced Sand Slopes. Soils and Foundations, 34(3), 21-37.

Huang, C.C., Tatsuoka, F., Sato, Y., 1994. Failure Mechanisms of Reinforced Sand Slopes Loaded with a Footing. Soils and Foundations, 34(2), 27-40.

Keskin, M.S., 2009. Güçlendirilmiş Kumlu Şevlere Oturan Yüzeysel Temellerin Deneysel ve Teorik Analizi. Doktora Tezi, Çukurova Üniversitesi, Fen Bilimleri Enstitüsü.

Keskin, M.S., Akgül, F., 2020. Şev Yakınına Oturan Yüzeysel Temellerin Taşıma Kapasitesinin Sayısal Analizi. DÜMF Mühendislik Dergisi, 11(1), 363-372.

Keskin, M.S., Laman, M., 2014. Experimental and Numerical Studies of Strip Footings on Geogrid-Reinforced Sand Slope. Arabian Journal for Science and Engineering, 39(3), 1607-1619.

Keskin, M.S., Laman, M., Aslan, F., 2007. Kumlu Şevlere Oturan Şerit Temellerin Analizi. Yapı Zemin, 159-164.

Lee, K.M., Manjunath, V.R., 2000. Experimental and Numerical Studies of Geosynthetic-Reinforced Sand Slopes Loaded with a Footing. Canadian Geotechnical Journal, 37(4), 828-842.

Meyerhof, G.G., 1951. The Ultimate Bearing Capacity of Foundations. Géotechnique, 2(4), 301-332.

Meyerhof, G.G., 1957. The Ultimate Bearing Capacity of Foundations on Slopes. 4th International Conference on Soil Mechanics and Foundation Engineering, London, 384-386.

Pınarlık, M., Öztürk Kardoğan, P.S., Kılıç Demircan, R., 2017. Şev Stabilitesine Zemin Özelliklerinin Etkisinin Limit Denge Yöntemi ile İrdelenmesi. Mühendislik Bilimleri ve Tasarım Dergisi, 5(3), 675-684.

PLAXIS 3D, 2019. Material Models Manual. R.B.J. Brinkgreve, L.M. Zampich, and N. Ragi Manoj, Eds., Delft.

Prandtl, L., 1921. Über die Eindringungsfestigkeit (Härte) plastischer Baustoffe und die Festigkeit von Schneiden. Zeitschrift für Angewandte Mathematik und Mechanik, 1(1), 15-20. (in German)

Saran, S., Sud, V.K., Handa, S.C., 1989. Bearing Capacity of Footings Adjacent to Slopes. Journal of Geotechnical Engineering, 115(4), 553-573.

Selvadurai, A.P.S., Gnanendran, C.T., 1989. An Experimental Study of a Footing Located on a Sloped Fill: Influence of a Soil Reinforcement Layer. Canadian Geotechnical Journal, 26(3), 467-473.

Shiau, J.S., Watson, J.F., 2008. 3D Bearing Capacity of Shallow Foundations Located near Deep Excavation Sites. International Conference on Deep Excavations (ICDE 2008), Singapore, 1-8.

Shields, D., Chandler, N., Garnier, J., 1990. Bearing Capacity of Foundations in Slopes. Journal of Geotechnical Engineering, 
116(3), 528-537.

Terzaghi, K., 1943. Theoretical Soil Mechanics. John Wiley \& Sons, New York.

Vesic, A.S., 1975. Bearing Capacity of Shallow Foundations. Foundation Engineering Handbook. H.F. Winterkorn and H.Y. Fang, Eds., Van Nostrand Reinhold, New York, 121-147.

Yoo, C., 2001. Laboratory Investigation of Bearing Capacity Behavior of Strip Footing on Geogrid-Reinforced Sand Slope. Geotextiles and Geomembranes, 19(5), 279-298. 